\title{
The gut microbiota of the wood-feeding termite Reticulitermes lucifugus (Isoptera; Rhinotermitidae)
}

\author{
Gabriella Butera $^{1,2}$ - Clelia Ferraro ${ }^{2}$ - Giuseppe Alonzo ${ }^{2}$. \\ Stefano Colazza ${ }^{2} \cdot$ Paola Quatrini $^{1}$
}

Received: 5 January 2015 / Accepted: 19 May 2015 / Published online: 9 June 2015

(C) Springer-Verlag Berlin Heidelberg and the University of Milan 2015

\begin{abstract}
Termite gut is host to a complex microbial community consisting of prokaryotes, and in some cases flagellates, responsible for the degradation of lignocellulosic material. Here we report data concerning the analysis of the gut microbiota of Reticulitermes lucifugus (Rossi), a lower termite species that lives in underground environments and is widespread in Italy, where it causes damage to wood structures of historical and artistic monuments. A 16S rRNA gene clone library revealed that the R. lucifugus gut is colonized by members of five phyla in the domain Bacteria: Firmicutes (49\% of clones), Proteobacteria (24\%), Spirochaetes (14\%), the candidatus TG1 phylum (12\%), and Bacteroidetes (1\%). A collection of cellulolytic aerobic bacteria was isolated from the gut of $R$. lucifugus by enrichment cultures on different cellulose and lignocellulose substrates. Results showed that the largest amount of culturable cellulolytic bacteria of R. lucifugus belongs to Firmicutes in the genera Bacillus and Paenibacillus (67\%). These isolates are also able to grow on xylan and show the largest clear zone diameter in the Congo red test. Reticulitermes lucifugus hosts a diverse community of bacteria and could be considered an acceptable source of hydrolytic enzymes for biotechnological applications.
\end{abstract}

Electronic supplementary material The online version of this article (doi:10.1007/s13213-015-1101-6) contains supplementary material, which is available to authorized users.

Paola Quatrini

paola.quatrini@unipa.it

1 Dipartimento di Scienze e Tecnologie Biologiche, Chimiche e Farmaceutiche, Università degli Studi di Palermo, Viale delle Scienze, Edif.16, 90128 Palermo, Italy

2 Dipartimento di Scienze Agrarie e Forestali, Università degli Studi di Palermo, Palermo, Italy
Keywords Termites · Gut microbiota $\cdot 16 \mathrm{~S}$ rDNA . Amplified ribosomal DNA restriction analysis (ARDRA) . Cellulose degradation

\section{Introduction}

The termite gut (Insecta: Isoptera) is an important ecosystem that hosts a variety of microbes, including bacteria, protists, fungi and archaea (Hongoh et al. 2003), and it is one that has fascinated many scientists, as host-microbe interactions are responsible for the efficient degradation of lignocellulose (Ohkuma 2003; Ni and Tokuda 2013). The gut can be described as an anaerobic gradient system which is constantly supplied with oxygen via the epithelium (Köhler et al. 2012). The gut microbiota is commonly exchanged between colony members and transmitted to the next generation via trophallaxis (proctodeal feeding), which can promote coevolutional diversification of symbiotic microbes along with host phylogeny (Tokuda et al. 2014). Termites comprise a complex assemblage of diverse species, roughly divided into lower and higher termites. Lower termites harbor a dense and diverse population of prokaryotes and flagellated protists in their gut (Ohkuma 2003). Protozoan symbionts residing in lower termites are responsible for lignocellulose digestion in this group. Their host-specific phylogeny and composition reflects the obligate (mutualistic) symbiotic association between protists and termites (Ohkuma 2008). Higher termites lack flagellates and harbor only prokaryotes in their highly structured guts; both higher and lower termites produce their own cellulolytic enzymes (Miyata et al. 2007; Köhler et al. 2012; Tokuda et al. 2012).

The characteristics of gut microbes have been extensively studied, and it is believed that microbes provide carbon, nitrogen and energy nutrition to their host termites, to the extent 
that termites can no longer live without them (Hongoh et al. 2003). Extensive reviews on the lignocellulose-degrading systems in termites and their symbiotic systems have recently been published (Hongoh 2011; Ni and Tokuda 2013; Brune 2014).

Reticulitermes lucifugus (Rossi) (Isoptera: Rhinotermitidae), along with Reticulitermes flavipes (Kollar) and the recently recorded Reticulitermes urbis Bagneres Uva et Clement, represent the most harmful pests for wooden objects and structural timbers as well as for historical and artistic wooden structures, thus representing a great threat to Italian cultural heritage (Liotta 1991; Liotta 2005; Perdereau et al. 2011). Only a few studies have focused specifically on the Italian range, concentrating primarily on species origin and evolution (Luchetti et al. 2013), and little information is available on the gut microbiota of this species. Previous studies focusing on the symbiotic microbial community of $R$. lucifugus described some species of symbiotic protozoa (Varrica 2004) and non-mycetocyte intracellular bacteria (Bandi et al. 1997), but no reports are available on gut symbiotic bacteria.

The study of symbiotic systems in the termite gut has often been hampered by the difficulty in isolating and cultivating a large number of gut microorganisms (Ohkuma 2001); as gut bacteria require strict environmental conditions for survival and reproduction, culturing techniques are often inadequate for their study. These problems have been overcome by the use of cultureindependent approaches that provide an effective opportunity for studying the phylogenetic species richness of termite gut bacteria (Husseneder et al. 2010). In particular, the analysis of 16S rRNA gene sequencing and fingerprinting has recently produced a steady flow of information on the species richness of the gut bacteria in a variety of termite species.

In this work, we investigated the gut microbial community of the lower termite $R$. lucifugus using a culture-independent approach. In order to isolate cellulolytic and hemicellulolytic bacteria, we also applied aerobic cultivation conditions using lignocellulose as substrate in enrichment cultures.

\section{Materials and methods}

\section{Termite collection}

Termites were obtained by traps located in the experimental fields at the Department of Agriculture and Forest Sciences (University of Palermo, Italy) and were transferred to the laboratory for analysis. Only worker caste termites were used for the experiments.

\section{DNA extraction, PCR, and cloning}

Approximately 100 termite workers were surface-sterilized in $70 \%$ ethanol (30 s) and rinsed in sterile water (four times); guts were then removed using sterilized forceps, placed in sterile distilled water (in order to obtain lysis of protozoan cells), and gently crushed using a sterilized pestle. Total DNA of the termite gut content was then extracted using the QIAamp ${ }^{\circledR}$ DNA Stool Kit (QIAGEN, Venlo, The Netherlands), according to the manufacturer's instructions. DNA concentration was determined using the Quant-i $\mathrm{T}^{\mathrm{TM}}$ dsDNA BR Assay Kit (Thermo Fisher Scientific, Waltham, MA, USA) in accordance with the manufacturer's instructions.

Total DNA was used as template for amplification of the nearly full-length bacterial 16S rRNA gene with the universal bacterial primers fD1 (5'-AGAGTTTGATCCTGGCTCAG$3^{\prime}$ ) and $\mathrm{rD1}$ (5'-AAGGAGGTGATCCAGCC-3') (Weisburg et al. 1991). PCR was performed using a Biometra ${ }^{\circledR}$ Tpersonal Thermal Cycler (Biometra GmbH, Göttingen, Germany). Each $100 \mu \mathrm{l}$ reaction (in $\mathrm{ddH}_{2} 0$ ) contained 80-100 ng DNA, 1 X PCR buffer, $1,5 \mathrm{mM} \mathrm{MgCl}_{2}, 0,25 \mathrm{mM}$ of dNTP, $5 \mathrm{U}$ of HotStarTaq (QIAGEN), and $0,2 \mu \mathrm{M}$ of each primer. The PCR was carried out under the following conditions: $15 \mathrm{~min}$ at $94{ }^{\circ} \mathrm{C}$ (hot start), 5 min at $94{ }^{\circ} \mathrm{C}$ and 30 cycles of 1 min at $94^{\circ} \mathrm{C}, 1 \mathrm{~min}$ at $55^{\circ} \mathrm{C}$ and $2 \mathrm{~min}$ at $72^{\circ} \mathrm{C}$; then an extension of 7 min at $72{ }^{\circ} \mathrm{C}$. PCR products were purified using a Nucleospin $^{\circledR}$ Extract II (MACHEREY-NAGEL GmbH \& Co. KG, Düren, Germany) according to manufacturer protocols. PCR products were visualized on ethidium bromide stained $1 \%$ agarose gel.

The PCR products were cloned into a $\mathrm{pCR}^{\circledR} 2.1-\mathrm{TOPO}^{\circledR}$ cloning vector using the TOPO TA Cloning Kit (Invitrogen), and TOP10 competent Escherichia coli cells were transformed according to manufacturer protocols. Plasmids were extracted from clones using an alkaline lysis mini-preparation procedure (Sambrook et al. 1989) and visualized on ethidium bromide-stained $1 \%$ agarose gel.

\section{ARDRA analysis and 16S rDNA gene sequencing}

Plasmids were double-digested with KpnI/SmaI and EcoRII NotI, according to manufacturer protocols (Invitrogen). The restriction fragments were visualized on $1 \%$ agarose gel in $1 X$ Tris-acetic acid-EDTA (TAE) buffer. Band sizes were quantified by comparison with a standard 100-bp DNA Ladder Mix (Fermentas; Thermo Fisher Scientific). Phylotypes were identified based on the two restriction profiles, and one or more (based on abundance) representative clones for each phylotype were randomly chosen and their plasmids purified using the QIAprep ${ }^{\circledR}$ Spin Miniprep Kit (QIAGEN). The inserts were sequenced using primer $\mathrm{fD} 1$, and the sequences were subjected to Ribosomal Database Project (RDP) classifier software analysis (http://rdp.cme.msu.edu/classifier/classifier.jsp), and to BLAST search (http://www.ncbi.nlm.nih.gov/blast). The sequences were submitted to the DDBJ/EMBL/GenBank database under accession numbers KP207659 to KP207683. 


\section{Enrichment cultures for isolation of cellulolytic and hemicellulolytic gut bacteria}

In order to isolate aerobic cellulolytic bacteria in the $R$. lucifugus gut, enrichment cultures were established on carboxymethylcellulose substrate and filter paper as the sole carbon source. Three other enrichment cultures containing powdered walnut, eucalyptus and pine wood as substrates, and were also carried out to select hemicellulolytic bacteria eventually present in the termite gut. To carry out enrichment cultures, $1 \mathrm{ml}$ of the disrupted gut contents was suspended in each of the five enrichment cultures flasks containing $20 \mathrm{ml}$ of Medium 1 (Wenzel et al. 2002a) and $0.1 \mathrm{~g}$ of carboxymethylcellulose (CMC) (Sigma-Aldrich Co. LLC, St. Louis, MO, USA), filter paper, and finely ground walnut, eucalyptus or pine wood, respectively. The cultures were aerobically incubated at $28^{\circ} \mathrm{C}$ for 4 weeks.

\section{Isolation of bacteria from enrichment cultures}

After incubation, aliquots of the enrichment cultures were serially diluted and inoculated onto Petri dishes containing four different solid media: Medium 2 and Medium 3 (Wenzel et al. 2002a), both supplemented with CMC or xylan (SigmaAldrich) $(5 \mathrm{~g} / \mathrm{l})$, respectively. After incubation at $28^{\circ} \mathrm{C}$ for $48 \mathrm{~h}$, all single colonies of $10^{-5}, 10^{-6}$ and $10^{-7}$ serial dilution plates were streaked to purity on the same fresh medium.

\section{Congo red dye test}

The cellulose degradation capacity of the isolates from all enrichments was tested on solid Medium 2 with CMC by covering the Petri dishes with a Congo red dye solution (Cacciari and Quatrini 2002). After dye removal, degradation was indicated by a clear zone around colonies, the size of which was measured in order to reveal the CMC-degrading capability of bacterial isolates on the solid medium used (Wenzel et al. 2002a).

\section{Colony PCR and identification of isolates}

All Congo red-positive isolates from termite gut were identified by $16 \mathrm{~S}$ gene sequencing. In order to amplify the $16 \mathrm{~S}$ rRNA gene of the isolates, a colony lysate was used as a PCR template without further DNA purification steps. A single colony was suspended in $25 \mu \mathrm{l}$ sterile Tris-EDTA buffer solution BioUltra, for molecular biology, $\mathrm{pH} 8.0$ (SigmaAldrich), boiled for $3 \mathrm{~min}$, and placed in ice for $5 \mathrm{~min}$. Insoluble material was separated from the liberated DNA by centrifugation (5 min at 13,000 rpm; Mikro 200 centrifuge; Andreas Hettich GmbH \& Co. KG, Tuttlingen, Germany). The supernatant containing the DNA was removed and used $(1-2 \mu \mathrm{l})$ as a template in PCR reactions using the universal bacteria primers $\mathrm{fD} 1$ and $\mathrm{rD} 1$ as described above. Sequence data were submitted to the DDBJ/EMBL/Genbank database under accession numbers KP207604 to KP207658.

\section{Results and discussion}

\section{Bacterial diversity in the Reticulitermes lucifugus gut}

The bacterial community of the gut of $R$. lucifugus was analyzed using a culture-independent approach based on the construction of a 16S rRNA gene clone library. DNA of good quality was extracted from 100 field-caught termite workers. The amplified 16S rRNA gene was cloned into $E$. coli, with approximately 280 clones obtained. One hundred clones were randomly chosen and investigated via amplified ribosomal DNA restriction analysis (ARDRA) using two double-digestions. Twenty-nine different profiles were scored, with the

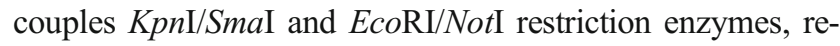
spectively. On the basis of combinations of the ARDRA profiles, 83 clones (after excluding those that gave double or unclear digestion profiles) were distributed into 23 phylotypes (operational taxonomic units, OTUs). One or more representative clones of each phylotype were sequenced, for a total of 52 clones (Table 1). The phylogeny of sequenced clones was obtained using the RDP classifier tool and BLAST search against the non-redundant nucleotide database. The BLAST search resulted in high identity percentages, largely with sequences of uncultivated bacteria (data not shown), while much lower identity results were obtained using the 16S RNA ribosomal sequences as database (Table 1).

Reticulitermes lucifugus gut is colonized by members of five phyla in the domain Bacteria: Firmicutes (49 \% of clones), Proteobacteria (24\%), Spirochaetes (14\%), the candidatus TG1 phylum (12\%), and Bacteroidetes (1\%). Among Firmicutes, the abundant population of fermentative bacteria such as members of the orders Clostridiales (represented by Clostridiaceae, Peptococcaceae and Ruminococcaceae) and Lactobacillales (Leuconostocaceae and Enterococcaceae) is consistent with the results of other studies to date on the bacterial community of the termites (Hongoh et al. 2003; Hongoh et al. 2006). Clostridia and lactic acid bacteria are involved in acetogenesis, sugar degradation and fermentation, and account for the largest diversity in Reticulitermes species (Husseneder et al. 2010).

Reticulitermes lucifugus harbors a large number of Proteobacteria, mainly affiliated to the $\beta$ - and $\delta$ proteobacteria. Delta-proteobacteria have been recognised as playing a major role in the $\mathrm{H}_{2}+\mathrm{CO}_{2}$ economy of termite hindgut communities; nitrogen-fixing Desulfovibrio strains have been isolated from the gut of termites (Ohkuma et al. 1996; Sato et al. 2009). 


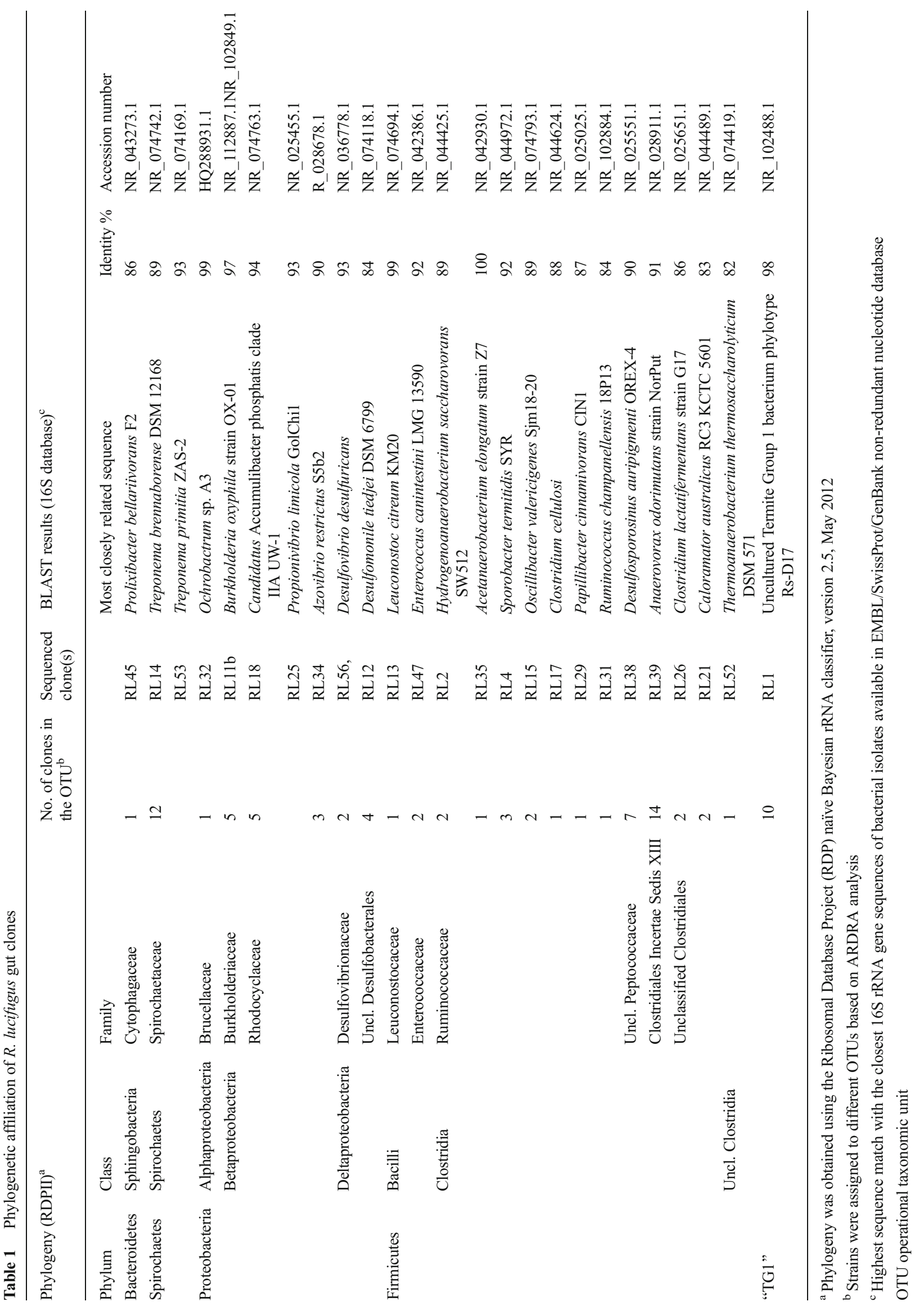


Spirochaetes are a major constituent of wood-feeding termite gut microbiota (Lilburn et al. 1999; Leadbetter et al. 1999), both in lower (Yang et al. 2005) and higher termites (Paster et al. 1996; Warnecke et al. 2007). In contrast, the population of Spirochaetes in the gut of fungus-growing and soil-feeding termites is lower (Hongoh et al. 2006; SchmittWagner et al. 2003) or absent (Shinzato et al. 2007). Most Spirochaetes are free-living in the gut fluid, and they have also been found as ectosymbionts attached to the surface of protists (Wenzel et al. 2002b). All of the Spirochaete sequences of $R$. lucifugus were assigned to the genus Treponema, with high identity with other Reticulitermes uncultured Spirochaetes (data not shown). The homoacetogenic Treponema primitia ZAS-2, which matches the $R$. lucifugus clone RL53 sequence, is one of three isolates that have been obtained in pure culture to date (Lucey and Leadbetter 2014). For these isolates, $\mathrm{CO}_{2}$ reducing acetogenesis and $\mathrm{N}_{2}$ fixation were demonstrated (Graber et al. 2004). In these same isolates, catechol 2,3dioxygenase and other essential meta-pathway genes involved in aromatic ring cleavage were observed for the first time in the phylum (Lucey and Leadbetter 2014).

TG-1 bacteria consist of as-yet-uncultivated diverse bacteria from a wide range of chemically and geographically distinct habitats. Members of this phylum, the so-called Endomicrobia (Hugenholtz et al. 1998), often predominate in the termite gut microbial communities (Ohkuma et al. 2007) as intracellular symbionts of cellulolytic gut protists (Ikeda-Ohtsubo et al. 2007). In R. lucifugus TG-1 bacteria account for $12 \%$ of the clone library, similar to the sister taxon Reticulitermes speratus (Kolbe) (Hongoh et al. 2003). The prokaryotic symbionts colonize the cell surface, the cytoplasm, and sometimes the nucleus of their host flagellates in the termite gut (Ikeda-Ohtsubo et al. 2007). The functional basis for such flagellate-prokaryote associations is largely unknown (Brune and Stingl 2006), but TG-1 bacteria are believed to play a key role in the symbiotic system of the termite gut by supplying nitrogenous compounds to their host protists and the termites (Hongoh et al. 2008). The diversity of Endomicrobia lineages of lower termites reflects a specific affiliation with their flagellate hosts. Notably, all Endomicrobia associated with flagellates of the genus Trichonympha collectively form a monophyletic group, which suggests cospeciation of this symbiotic pair (Ikeda-Ohtsubo et al. 2007). Previous studies focused on the symbiotic protozoan community of $R$. lucifugus have described five species: Dynenympha sp., Pyrsonympha flagellata Leidy, Spyrotriconympha flagellata Grassi e Foà, Holomastigotes elongatum, and Trichonympha agilis Leidy (Varrica 2004). The clone library of $R$. lucifugus that we constructed is comprehensive of the bacterial symbionts inside the protozoa, as lysis of the protozoa was verified by microscopy observations of lysate samples. The majority of clones from $R$. lucifugus are affiliated with an Endomicrobia bacterium strictly related to
Trichonympha flagellates, as described in R. lucifugus and reported from the gut of many other termite species and the wood-feeding cockroach, Cryptocercus punctulatus Scudder (Dictyoptera: Cryptocercidae) (Ikeda-Ohtsubo and Brune 2009).

Bacteroidetes were found in low concentrations (1\%) in $R$. lucifugus, in contrast to the abundance found in Reticulitermes santonensis (Feytaud) (Yang et al. 2005) and R. flavipes (Boucias et al. 2013). Members of the phylum Bacteroidetes have been reported to reside in the gut as ecto- or endosymbionts of flagellated protozoa (Noda et al. 2005; Nakajima et al. 2006), and cellularlevel symbioses between Bacteroidales and gut protists are as common as those between spirochetes and gut protists. The Bacteroidales bacteria in termite guts, including symbionts of protists, constitute several monophyletic clusters specific to termites and wood-feeding cockroaches. The sequence of the $R$. lucifugus clone, in particular, was $94 \%$ identical to that detected in the termite Hodotermopsis sjoestedti (Nakajima et al. 2006). The ecological roles of these bacteria remain unclear; many Bacteroidales are polysaccharide-fermenting anaerobes, some of them producing cellulases and other fiberdegrading enzymes, which may complement enzyme activity lacking in the host. They may also protect their obligate anaerobic hosts by maintaining an oxygen-free environment (Noda et al. 2006).

Our work represents the first study on the bacterial community of the R. lucifugus gut. A good picture of the insect microbiota was obtained by analysing the 16 SrRNA clone library, although the rarefaction curve did not reach saturation level (data not shown). A higher number of clones or application of next-generation sequencing techniques would likely be necessary to capture the whole diversity of Reticulitermes gut bacterial community.

\section{The cultivable cellulolytic bacteria of Reticulitermes lucifugus gut}

Termites may be considered rich reservoirs of bacteria that synthesise enzymes involved in the process of lignocellulose degradation. The termite gut is a well-aerated anaerobic gradient system, where aerobic bacteria are also present (Wenzel et al. 2002a). Few cellulose-degrading bacteria have been isolated and identified from certain termite species because of the difficulty in isolating and cultivating a large number of gut microorganisms (Ohkuma 2001; Wenzel et al. 2002a).

In order to isolate the cellulolytic bacteria in the R. lucifugus gut, enrichment cultures were established on carboxymethylcellulose and filter paper as substrates. Three other enrichment cultures containing walnut, eucalyptus and pine wood as substrates were also carried out for selection of hemicellulolytic 
Table 2 Results of isolation of cellulolytic gut bacteria from enrichment cultures on different media using various lignocellulose substrates as $\mathrm{C}$ source

\begin{tabular}{lrrrrr}
\hline Enrichment & \multicolumn{2}{l}{ Number of isolates on isolation media } & \multirow{2}{*}{ Cellulolytic isolates $^{\text {b }}$} \\
\cline { 2 - 5 } & \multicolumn{1}{l}{ W2 } & \multicolumn{2}{c}{ W3 } & \\
\hline C source & CMC $^{\mathrm{a}}$ & Xyl & CMC & Xyl & $\%$ \\
CMC & 23 & 6 & 5 & 1 & 37.1 \\
Walnut wood & 10 & 34 & 0 & 22 & 6.1 \\
Eucalyptus wood & 20 & 23 & 20 & 17 & 10.0 \\
Filter paper & 16 & 15 & 16 & 14 & 35.0 \\
Pine wood & 10 & 21 & 12 & 11 & 22.2 \\
All & 79 & 99 & 53 & 65 & 19.7 \\
\hline
\end{tabular}

After 1 month of incubation, the cultures were inoculated on W2 and W3 solid media containing CMC and xylan, respectively

$C M C$ carboxymethylcellulose

a The composition of W2 andW3 media is reported in the "Materials and Methods" section

${ }^{\mathrm{b}}$ Positive isolates to the Congo red test bacteria. The cultures were aerobically incubated at $28^{\circ} \mathrm{C}$, and after 4 weeks, aliquots of the enrichment cultures were serially diluted and inoculated onto four different solid media plates: Medium 2 and Medium 3, both supplemented with CMC or xylan, respectively. After incubation, all single colonies of the most diluted plates were streaked to purity, and a collection of 296 isolates was obtained from the enrichment cultures (Table 2). Medium 2 was found to be more suitable than Medium 3 (both in the presence of CMC or xylan as carbon source) for selection of cellulolytic bacteria. The 296 putative cellulolytic bacterial isolates were analysed using the Congo red test, and 58 displayed a clear zone approximately $1 \mathrm{~cm}$ or larger around the colonies (Supplementary table S1). CMC was the enrichment substrate that selected the lowest number of isolates (35) but the highest percentage of Congo redpositive strains. Conversely, a high number of isolates were obtained from Eucalyptus wood enrichment cultures, but only $10 \%$ revealed positivity to the Congo red test.

\section{Phylogenetic analysis of cellulolytic isolates}

The isolates with positive Congo red test results were assigned to three phyla (Actinobacteria, Firmicutes and Proteobacteria) and 12 genera (Table 3). The largest proportion of culturable cellulolytic bacteria of $R$. lucifugus belonged to Firmicutes, in the genera Bacillus and Paenibacillus (67 \%), which also showed the largest clear zone diameter in the Congo red test (Supplementary Table S1). Most of the isolates showing the highest CMC degradation ability were related to the Bacillus cereus/B. thuringiensis group. Some of them derive from xylan-containing plates (Supplementary Table S1), suggesting that they also have hemicellulolytic activity (Tseng et al. 2001; Chang et al. 2004). These cellulolytic strains likely belong to new species, and their hydrolytic enzymes may be worthy of further investigation for biotechnological applications (König 2006; Wang et al. 2008). Among Actinobacteria, Microbacterium species are known to produce enzymes

Table 3 Identification of cellulolytic bacteria isolated from enrichment cultures

\begin{tabular}{|c|c|c|c|c|}
\hline Phylum & Class & Family & Genus & Number of isolates \\
\hline "Actinobacteria" & Actinobacteria & Microbacteriaceae & Microbacterium & 4 \\
\hline \multirow[t]{2}{*}{ Firmicutes } & \multirow[t]{2}{*}{ Bacilli } & \multirow[t]{2}{*}{ Bacillaceae 1} & Bacillus & 38 \\
\hline & & & Paenibacillus & 1 \\
\hline \multirow[t]{9}{*}{ Proteobacteria } & \multirow[t]{3}{*}{ Alphaproteobacteria } & Caulobacteraceae & Brevundimonas & 2 \\
\hline & & Rhizobiaceae & Rhizobium & 2 \\
\hline & & Sphingomonadaceae & Novosphingobium & 3 \\
\hline & \multirow[t]{5}{*}{ Betaproteobacteria } & \multirow[t]{4}{*}{ Comamonadaceae } & Delftia & 2 \\
\hline & & & Hydrogenophaga & 1 \\
\hline & & & Ramlibacter & 1 \\
\hline & & & Variovorax & 2 \\
\hline & & Rhodocyclaceae & Shinella & 1 \\
\hline & Gammaproteobacteria & Enterobacteriaceae & Citrobacter & 1 \\
\hline
\end{tabular}


involved in cellulose and xylan degradation (Okeke and $\mathrm{Lu}$ 2011), and were also isolated from the higher termite Zootermopsis angusticollis (Wenzel et al. 2002a).

Among Alphaproteobacteria, Brevundimonas and Rhizobium are known cellulose degraders, and sphingomonads of the family Sphingomonadaceae are known to synthesize numerous oxygenases and glycoside hydrolases, which are likely responsible for the degradation of various recalcitrant aromatic compounds and polysaccharides (Aylward et al. 2013). Novosphingobium has never before been isolated from termites, and beyond cellulolytic activity, kraft lignin biodegradation was demonstrated for a Novosphingobium (Chen et al. 2012). Unexpected diversity of Comamonadaceae was detected in the R. lucifugus gut. To our knowledge, only one member of the genus Comamonas has been isolated from a termite thus far (Chou et al. 2007). The hydrolytic/cellulolytic activity of members of the family Comamonadaceae has been described for soil bacteria of the genera Variovorax and Delftia (Talia et al. 2012); several glycosyl hydrolase-encoding genes originating from Comamonadaceae were recently detected in the metagenome from casts of two earthworm species (Beloqui et al. 2010). We were also able to isolate facultative anaerobes of the family Enterobacteriaceae. Specifically, the isolate was identified as Citrobacter farmeri, which has also been isolated from the subterranean termite Coptotermes formosanus Shiraki (Adams and Boopathy 2005). The role of facultative organisms in the termite gut may be the scavenging of oxygen and the creation of anaerobic conditions for anaerobic microorganisms essential for the digestion of cellulose consumed by the termite.

Reticulitermes lucifugus is widespread in Italy, and its microbiota was investigated here for the first time. The cultureindependent approach revealed that $R$. lucifugus hosts a large and diverse community of aerobic and anaerobic bacteria. A collection of cellulolytic and hemicellulolytic bacterial isolates was obtained from the $R$. lucifugus gut. These bacteria represent a high value of biodiversity that can be exploited for biotechnological applications in the conversion of lignocellulose into bioethanol.

The next research steps should be the investigation of biochemical and physiological properties of these strains by characterization of their hydrolytic enzymes. The cultureindependent approach used here also allowed the identification of other uncultured key microbes sustaining termite xylophagy that are potential producers of hydrolytic enzymes. These microorganisms can be exploited by metagenome expression cloning (Lämmle et al. 2007). Reticulitermes lucifugus can be considered an acceptable source of hydrolytic enzymes for application in the conversion of lignocellulose into biofuels.

Acknowledgments The authors thank G. Varrica for insect collection and dissections.

\section{References}

Adams L, Boopathy R (2005) Isolation and characterization of enteric bacteria from the hindgut of Formosan termite. Bioresour Technol 96:1592-8

Aylward FO, McDonald BR, Adams SM, Valenzuela A, Schmidt RA, Goodwin LA, Woyke T, Currie CR, Suen G, Poulsen M (2013) Comparison of 26 sphingomonad genomes reveals diverse environmental adaptations and biodegradative capabilities. Appl Environ Microbiol 79:3724-33. doi:10.1128/AEM.00518-13

Bandi C, Sironi M, Nalepa CA, Corona S, Sacchi L (1997) Phylogenetically distant intracellular symbionts in termites. Parassitologia 39:71-5

Beloqui A, Nechitaylo TY, López-Cortés N, Ghazi A, Guazzaroni ME, Polaina J, Strittmatter AW, Reva O, Waliczek A, Yakimov MM, Golyshina OV, Ferrer M, Golyshin PN (2010) Diversity of glycosyl hydrolases from cellulose-depleting communities enriched from casts of two earthworm species. Appl Environ Microbiol 76:5934-46

Boucias DG, Yunpeng CAI, Yijun S, Verena-Ulrike L (2013) The hindgut lumen prokaryotic microbiota of the termite Reticulitermes flavipes and its responses to dietary lignocellulose composition. Mol Ecol 22:1836-1853

Brune A, Stingl U (2006) Prokaryotic symbionts of termite gut flagellates: phylogenetic and metabolic implications of a tripartite symbiosis. In: Overmann J (ed) Molecular Basis of Symbiosis. Springer, Berlin, pp 39-60

Brune A (2014) Symbiotic digestion of lignocellulose in termite guts. Nat Rev Microbiol 12:168-80

Cacciari I, Quatrini P (2002) I gruppi fisiologici del ciclo del carbonio. In: "Metodi di analisi microbiologica del suolo" G Picci e P Nannipieri (coord.). Ministero delle politiche agricole e forestali, Soc. Ital. Scienza del Suolo. Franco Angeli Ed. Parte III, 9 pp.74-75

Chang P, Tsai WS, Tsai CL, Tseng MJ (2004) Cloning and characterization of two thermostable xylanases from an alkaliphilic Bacillus firmus. Biochem Biophys Res Commun 319:1017-1025

Chen Y, Chai L, Tang C, Yang Z, Zheng Y, Shi Y, Zhang H (2012) Kraft lignin biodegradation by Novosphingobium sp. B-7 and analysis of the degradation process. Bioresource Technol 123:682-685

Chou JH, Sheu SY, Lin KY, Chen WM, Arun AB, Young CC (2007) Comamonas odontotermitis sp. nov., isolated from the gut of the termite Odontotermes formosanus. Int J Syst Evol Microbiol 57:887-91

Graber JR, Leadbetter JR, Breznak JAW (2004) Description of Treponema azotonutricium sp. nov. and Treponema primitia sp. nov., the first spirochaetes isolated from termite guts. Appl Environ Microbiol 70:1315-1320

Hongoh Y, Ohkuma M, Kudo T (2003) Molecular analysis of bacterial microbiota in the gut of the termite Reticulitermes speratus (Isoptera; Rhinotermitidae). FEMS Microbiol Ecol 44:231-42. doi:10.1016/S0168-6496(03)00026-6

Hongoh Y, Deevong P, Hattori S, Inoue T, Noda S, Noparatnaraporn N, Kudo T, Ohkuma M (2006) Phylogenetic diversity, localization, and cell morphologies of members of the candidate phylum TG3 and a subphylum in the phylum Fibrobacteres, recently discovered bacterial groups dominant in termite guts. Appl Environ Microbiol 72: 6780-6788

Hongoh Y, Sharma VK, Prakash T, Noda S, Taylor TD, Kudo T, Sakaki Y, Toyoda A, Hattori M, Ohkuma M (2008) Complete genome of the uncultured Termite Group 1 bacteria in a single host protist cell. Proc Natl Acad Sci U S A 105(14):5555-60. doi:10.1073/pnas. 0801389105

Hongoh Y (2011) Toward the functional analysis of uncultivable, symbiotic microorganisms in the termite gut. Cell Mol Life Sci 68:1311-25

Hugenholtz P, Goebel BM, Pace NR (1998) Impact of cultureindependent studies on the emerging phylogenetic view of bacterial diversity. J Bacteriol 180:4765-4774 
Husseneder C, Ho H-Y, Blackwell M (2010) Comparison of the bacterial symbiont composition of the Formosan subterranean termite from its native and introduced range. Open J Microbiol 4:53-66

Ikeda-Ohtsubo W, Desai M, Stingl U, Brune A (2007) Phylogenetic diversity of "Endomicrobia" and their specific affiliation with termite gut flagellates. Microbiology 153:3458-3465

Ikeda-Ohtsubo W, Brune A (2009) Cospeciation of termite gut flagellates and their bacterial endosymbionts: Trichonympha species and "Candidatus Endomicrobium trichonymphae". Mol Ecol 18:332342

Köhler T, Dietrich C, Scheffrahn RH, Brune A (2012) High-resolution analysis of gut environment and bacterial microbiota reveals functional compartmentation of the gut in wood-feeding higher termites (Nasutitermes spp.). Appl Environ Microbiol 78:4691-701

Konig H (2006) Bacillus species in the intestine of termites and other soil invertebrates. J Appl Microbiol 101:620-627

Lämmle K, Zipper H, Breuer M, Hauer B, Buta C, Brunner H, Rupp S (2007) Identification of novel enzymes with different hydrolytic activities by metagenome expression cloning. J Biotechnol 127: $575-92$

Leadbetter JR, Schmidt TM, Graber JR, Breznak JA (1999) Acetogenesis from $\mathrm{H}_{2}$ plus $\mathrm{CO}_{2}$ by spirochetes from termite guts. Science 283: $686-9$

Lilburn TG, Schmidt TM, Breznak JA (1999) Phylogenetic diversity of termite gut spirochaetes. Environ Microbiol 1:331-345

Liotta G (1991) Gli insetti e i danni del legno. Collana: Arte e Restauro Strumenti. Nardini Editore.

Liotta G (2005) Termites that deteriorate wooden structures in cultural heritage. Conservation of historic wooden structures: proceedings of the international conference, Florence 22-27 February, 2005. Voll. 1 and 2

Lucey KS, Leadbetter JR (2014) Catechol 2,3-dioxygenase and other meta-cleavage catabolic pathway genes in the 'anaerobic' termite gut spirochete Treponema primitia. Mol Ecol 23:1531-43

Luchetti A, Scicchitano V, Mantovani B (2013) Origin and evolution of the Italian subterranean termite Reticulitermes lucifugus (Blattodea, Termitoidae, Rhinotermitidae). Bull Entomol Res 103:734-41

Miyata R, Noda N, Tamaki H, Kinjyo K, Aoyagi H, Uchiyama H, Tanaka H (2007) Influence of feed components on symbiotic bacterial community structure in the gut of the wood-feeding higher termite Nasutitermes takasagoensis. Biosci Biotechnol Biochem 71:1244-51

Nakajima H, Hongoh Y, Noda S, Yoshida Y, Usami R, Kudo T, Ohkuma M (2006) Phylogenetic and morphological diversity of Bacteroidales members associated with the gut wall of termites. Biosci Biotechnol Biochem 70:211-218

Ni J, Tokuda G (2013) Lignocellulose-degrading enzymes from termites and their symbiotic microbiota. Biotechnol Adv 31:838-50

Noda S, Iida T, Kitade O, Nakajima H, Kudo T, Ohkuma M (2005) Endosymbiotic Bacteroidales bacteria of the flagellated protist Pseudotrichonympha grassii in the gut of the termite Coptotermes formosanus. Appl Environ Microbiol 71:8811-8817

Noda S, Inoue T, Hongoh Y, Kawai M, Nalepa CA, Vongkaluang C et al (2006) Identification and characterization of ectosymbionts of distinct lineages in Bacteroidales attached to flagellated protists in the gut of termites and a wood-feeding cockroach. Environ Microbiol 8: $11-20$

Ohkuma M, Noda S, Usami R, Horikoshi K, Kudo T (1996) Diversity of Nitrogen Fixation Genes in the Symbiotic Intestinal Microflora of the Termite Reticulitermes speratus. Appl Environ Microbiol 62: 2747-52

Ohkuma M (2001) Symbiosis within the gut microbial community of termites. RIKEN Rev 41:69-72

Ohkuma M (2003) Termite symbiotic systems: efficient bio-recycling of lignocellulose. Appl Microbiol Biotechnol 61:1-9

Ohkuma M, Sato T, Noda S, Ui S, Kudo T, Hongoh Y (2007) The candidate phylum "Termite Group 1" of bacteria: Phylogenetic diversity, distribution, and endosymbiont members of various gut flagellated protists. FEMS Microbiol Ecol 60:467-476

Ohkuma M (2008) Symbioses of flagellates and prokaryotes in the gut of lower termites. Trends Microbiol 16:345-52

Okeke BC, Lu J (2011) Characterization of a Defined Cellulolytic and Xylanolytic Bacterial Consortium for Bioprocessing of Cellulose and Hemicelluloses. Appl Biochem Biotechnol 163:869-881

Paster BJ, Dewhirst FE, Cooke SM, Fussing V, Poulsen LK, Breznak JA (1996) Phylogeny of not-yet-cultured spirochaetes from termite guts. Appl Environ Microbiol 62:347-352

Perdereau E, Dedeine F, Christides JP, Dupont S, Bagnères AG (2011) Competition between invasive and indigenous species: an insular case study of subterranean termites. Biol Invasions 13:1457-1470

Sambrook J, Fritsch EF, Maniatis T (1989) Molecular Cloning, a Laboratory Manual, 2nd edn. Cold Spring Harbor Laboratory Press, New York

Sato T, Hongoh Y, Noda S, Hattori S, Ui S, Ohkuma M (2009) Candidatus Desulfovibrio trichonymphae, a novel intracellular symbiont of the flagellate Trichonympha agilis in termite gut. Environ Microbiol 11:1007-15. doi:10.1111/j.1462-2920.2008.01827.x

Schmitt-Wagner D, Friedrich MW, Wagner B, Brune A (2003) Phylogenetic diversity, abundance, and axial distribution of bacteria in the intestinal tract of two soilfeeding termites (Cubitermes spp.). Appl Environ Microbiol 69:6007-6017

Shinzato N, Muramatsu M, Matsui T, Watanabe Y (2007) Phylogenetic Analysis of the Gut Bacterial Microflora of the Fungus-Growing Termite Odontotermes formosanus. Biosci Biotechnol Biochem 71:906-915

Talia P, Sede SM, Campos E, Rorig M, Principi D, Tosto D, Hopp HE, Grasso D, Cataldi A (2012) Biodiversity characterization of cellulolytic bacteria present on native Chaco soil by comparison of ribosomal RNA genes. Res Microbiol 163:221-32. doi:10.1016/j. resmic.2011.12.001

Tokuda G, Watanabe H, Hojo M, Fujita A, Makiya H, Miyagi M, Arakawa G, Arioka M (2012) Cellulolytic environment in the midgut of the wood-feeding higher termite Nasutitermes takasagoensis. J Insect Physiol 58:147-54. doi:10.1016/j.jinsphys.2011.10.012

Tokuda G, Tsuboi Y, Kihara K, Saitou S, Moriya S, Lo N, Kikuchi J (2014) Metabolomic profiling of 13C-labelled cellulose digestion in a lower termite: insights into gut symbiont function. Proc Biol Sci 281:20140990. doi:10.1098/rspb.2014.0990

Tseng Y, Ratanakhanokchai K, Shui-Tein C (2001) Purification and characterization of two cellulase free xylanases from an alkaliphilic Bacillus firmus. Enzyme Microb Technol 30:590-595

Varrica G (2004) “ Le tèrmiti in ambiente urbano: riflessi sul patrimonio culturale e studi comportamentali". PhD thesis. University of Palermo

Wang CM, Shyu CL, Ho SP, Chiou SH (2008) Characterization of a novel thermophilic, cellulose degrading bacterium Paenibacillus sp. strain B39. Lett Appl Microbiol 47:46-53

Warnecke F, Luginbühl P, Ivanova N, Ghassemian M, Richardson TH, Stege JT, Cayouette M et al (2007) Metagenomic and functional analysis of hindgut microbiota of a wood-feeding higher termite. Nature 450:560-565

Weisburg WG, Barns SM, Pelletier DA, Lane DJ (1991) 16S Ribosomal DNA amplification for phylogenetic study. J Bacteriol 697-703.

Wenzel M, Schoönig I, Berchtold M, Kämpfer P, König H (2002a) Aerobic and facultatively anaerobic cellulolytic bacteria from the gut of the termite Zootermopsis angusticollis. J Appl Microbiol 92:32-40

Wenzel M, Radek R, Brugerolle G, König H (2002b) Identification of the ectosymbiotic bacteria of Mixotricha paradoxa involved in movement symbiosis. Eur J Protistol 39:11-23

Yang H, Schmitt-Wagner D, Stingl U, Brune A (2005) Niche heterogeneity determines bacterial community structure in the termite gut (Reticulitermes santonensis). Environ Microbiol 7:916-932 